\title{
Avaliação de um sistema de secagem solar para o beneficiamento de caulim: cobertura de policarbonato $x$ cobertura de polipropileno
}

\author{
Evaluation of a solar drying system for kaolin processing: polycarbonate coating $\mathbf{x}$ polypropylene \\ coating
}

Evaluación de un sistema de secado solar para el procesamiento de caolín: recubrimiento de policarbonato $\mathrm{x}$ recubrimiento de polipropileno

\section{Resumo}

Esse trabalho teve o objetivo de contribuir para avaliar um sistema de secagem solar usado na secagem de caulim, que se encontra em desenvolvimento na região da Província Pegmatítica da Borborema (PPB), entre os estados da Paraíba e Rio Grande do Norte. Os experimentos foram realizados em um secador solar de exposição direta e na secagem solar ao ar livre. Foram testados dois protótipos de secadores com diferentes tipos de cobertura, um com cobertura de policarbonato e outro com cobertura de polipropileno, para avaliar a influência da cobertura transparente quanto a eficiência do processo de secagem. Foi realizada uma comparação entre os dois secadores e a secagem solar ao ar livre, sendo avaliado o tempo de secagem do caulim e o rendimento térmicos dos equipamentos. A quantidade de água retirada do caulim por unidade de tempo e o consumo específico de energia foram outros indicadores avaliados para cada processo de secagem, e foram importantes para corroborar a necessidade de utilização de novas tecnologias de secagem na região da PPB que dispõe de elevada intensidade de irradiação solar incidente durante todo o ano, mas que ainda utiliza lenha como energético para realizar a etapa de secagem no beneficiamento do caulim. Os principais resultados experimentais obtidos mostraram que a secagem solar nos secadores reduziu a umidade do caulim de $30 \%$ para $5 \%$, deixando-o em condições de seguir para a próxima etapa de beneficiamento, 240 minutos mais rápido em comparação 
com a secagem solar ao ar livre. Foi possível observar que o secador solar com cobertura de policarbonato se mostrou mais eficiente termicamente em comparação ao secador com cobertura de polipropileno. Novos experimentos estão sendo realizados buscando inserir a energia solar como energético de maior protagonismo, substituindo a lenha e visando melhorar a eficiência do processo de secagem e dar sustentabilidade as ações no beneficiamento do caulim, na região da PPB.

Palavras-chave: Secagem de caulim; Secador solar; Rendimento térmico; Energia solar.

\begin{abstract}
This work aimed to contribute to the evaluation of a solar drying system used in the drying of kaolin, which is under development in the region of the Pegmatitic Province of Borborema (PPB), between the states of Paraíba and Rio Grande do Norte. The experiments were carried out in a direct exposure solar dryer and outdoor solar drying. Two prototype dryers with different types of coverage were tested, one with a polycarbonate coating and the other with a polypropylene coating, to evaluate the influence of the transparent coating on the efficiency of the drying process. A comparison was also made between the two dryers and outdoor solar drying, evaluating the drying time of kaolin and the thermal efficiency of the equipment. The amount of water removed from the kaolin per unit of time and the specific energy consumption were other indicators evaluated for each drying process, and were important to corroborate the need to use new drying technologies in the PPB region, which has high intensity incident solar irradiation throughout the year, but which still uses firewood as energy source to carry out the drying step in the kaolin processing. The main experimental results obtained showed that solar drying in the dryers reduced kaolin moisture from $30 \%$ to $5 \%$, leaving it in a position to proceed to the next processing step, 240 minutes faster compared to solar air drying free. It was already possible to observe that the solar dryer with polycarbonate cover proved to be more thermally efficient compared to the dryer with polypropylene cover. New experiments are being carried out seeking to insert solar energy as a major energy source, replacing firewood and aiming to improve the efficiency of the drying process and give sustainability to the kaolin processing actions in the PPB region.
\end{abstract}

Keywords: Kaolin drying; Solar dryer; Thermal yield; Solar energy.

\title{
Resumen
}

Este trabajo tuvo como objetivo contribuir a la evaluación de un sistema de secado solar utilizado en el secado de caolín, que se encuentra en desarrollo en la región de la Provincia Pegmatítica de Borborema (PPB), entre los estados de Paraíba y Rio Grande do Norte. Los experimentos se llevaron a cabo en un secador solar de exposición directa y secado solar al aire libre. Se probaron dos prototipos de secadores con diferentes tipos de cobertura, uno con revestimiento de policarbonato y otro con revestimiento de polipropileno, para evaluar la influencia del revestimiento transparente en la eficiencia del proceso de secado. También se realizó una comparación entre los dos secadores y el secado solar exterior, evaluando el tiempo de secado del caolín y la eficiencia térmica del equipo. La cantidad de agua extraída del caolín por unidad de tiempo y el consumo específico de energía fueron otros indicadores evaluados para cada proceso de secado, y fueron importantes para corroborar la necesidad de utilizar nuevas tecnologías de secado en la región de PPB, que tiene irradiación solar incidente de alta intensidad. durante todo el año, pero que todavía utiliza leña como fuente de energía para realizar la etapa de secado en el procesamiento del caolín. Los principales resultados experimentales obtenidos mostraron que el secado solar en los secadores redujo la humedad del caolín de 30\% a 5\%, dejándolo en condiciones de pasar al siguiente paso de procesamiento, 240 minutos más rápido en comparación con el secado con aire solar libre. Ya se pudo observar que el secador solar con cubierta de policarbonato demostró ser más eficiente térmicamente en comparación con el secador con cubierta de polipropileno. Se están realizando nuevos experimentos que buscan insertar la energía solar como principal fuente de energía, en sustitución de la leña y con el objetivo de mejorar la eficiencia del proceso de secado y dar sostenibilidad a las acciones de procesamiento del caolín en la región del PPB.

Palabras clave: Secado de caolín; Secador solar; Rendimiento térmico; Energía solar.

\section{Introdução}

A evolução tecnológica levou o homem a um consumo cada vez maior de energia e recursos naturais em todas as formas disponíveis, cujo crescimento exponencial teve início com a Revolução Industrial. Este crescimento não dá sinais de que possa diminuir, contribuindo para uma matriz energética amplamente baseada nos combustíveis fósseis, com uso intensivo de gás natural e derivados de petróleo. 
Colocar o conhecimento científico a serviço do desenvolvimento sustentável da humanidade, respeitando os recursos naturais e privilegiando a eficiência energética deve ser a meta do pesquisador moderno, principalmente em países como o Brasil, que tem recursos energéticos renováveis disponíveis e precisa crescer para propiciar seu desenvolvimento.

A secagem é uma operação de transferência de calor e massa, por meio da qual ocorre a redução do teor de água do produto, mediante o fornecimento de energia. $\mathrm{O}$ controle do processo de secagem e o conhecimento do mecanismo do movimento de água no produto são fundamentais, uma vez que com dados de simulação e/ou experimental, pode-se obter condições ótimas no processo, minimizando as perdas e reduzindo o consumo de energia.

O objetivo deste trabalho foi avaliar a utilização de diferentes coberturas (policarbonato e polipropileno) em secadores usados para a secagem solar de minério do caulim na região da Província Pegmatítica da Borborema (PPB), para substituir, mesmo que parcialmente, o atual sistema de secagem solar a céu aberto ou em fornos com queima de lenha, tornando a etapa de secagem mais eficiente do ponto de vista energético do processo e contribuir para uma produção de caulim sustentável.

\section{Caulim}

O termo caulim é utilizado tanto para denominar a rocha que contém a caulinita, como o seu principal constituinte, quanto para o produto resultante do seu beneficiamento. Caulim é uma rocha de granulometria fina, constituída de material argiloso, normalmente com baixo teor de ferro, de cor branca ou quase branca (Grim, 1958).

Em função de suas propriedades físicas e químicas, o caulim pode ser utilizado em uma grande variedade de produtos, com destaque para o seu uso na fabricação de papéis comuns e revestidos, cerâmicas e refratários (Industrial Minerals, 2001).

Segundo Murray (1986), o caulim é uma importante matéria prima para as seguintes indústrias:

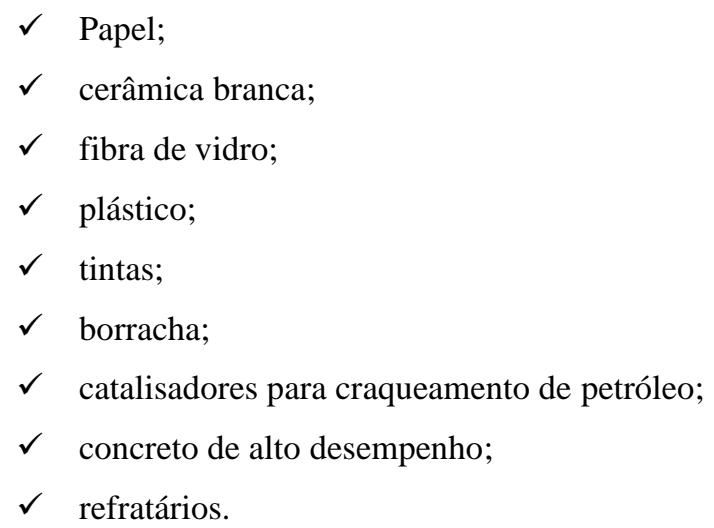

Outras aplicações são: cimento branco, pesticidas, vidros, adesivos, cosméticos etc.

\section{Sistema de Secagem Solar de Exposição Direta}

A utilização da energia solar como alternativa para a realização de secagem tem-se mostrado viável tecnicamente e economicamente. $\mathrm{O}$ processo pode ser realizado a céu aberto ou em um equipamento chamado secador solar.

O secador solar de exposição direta é composto pelo coletor solar, que é uma estrutura construída de material isolante térmico, possui uma cobertura transparente responsável pelo efeito estufa no interior e consequente aquecimento do ar circundante e uma bandeja onde o produto a ser seco é depositado. De modo geral, sua construção é simples e de baixo custo.

A opção por este tipo de equipamento se deu por ser simples e de fácil construção, rentável, exige menor manutenção, é de fácil manuseio e transporte e é útil para o processamento de vários produtos, como minérios, fatias de frutas e vegetais (Kumar; Singh, 2020).

Além disso em comparação com o secador solar de exposição indireta e secadores híbridos, os secadores solares de 
exposição direta apresentam maior rendimento térmico, ficando entre 20\% e 40\% (Kumar et al. 2016).

O desenvolvimento de secadores solares tem sido objeto de estudo de diversos pesquisadores em instituições de ensino nacionais e internacionais. Peneiro (2010) realizou diversos ensaios com secadores, determinando a eficiência para diferentes condições e produtos.

\section{Metodologia}

Com o objetivo de avaliar os sistemas de secagem propostos neste trabalho, esta é uma pesquisa de natureza quantitativa, a qual tem por objetivo demonstrar, de forma quantificada, a importância dos dados coletados em uma verificação experimental (Proetti, 2018).

Os secadores solares desenvolvidos, a saber, um com cobertura de policarbonato e outro com cobertura de polipropileno, são adaptações do sistema de secagem desenvolvidos e testados por Fernandes (2021) e Gomes (2021). Suas principais características construtivas são:

$\checkmark \quad$ Painel de fibras de média densidade conhecido comercialmente como Medium Density Fiberboard (MDF);

$\checkmark$ Utilização de uma telha de fibrocimento pintada de preto fosco, usada como capacitor térmico;

$\checkmark$ Tela de nylon;

$\checkmark$ Volume interno de 55 litros;

$\checkmark$ Cobertura de policarbonato alveolar transparente $4 \mathrm{~mm}$;

$\checkmark$ Cobertura de polipropileno fosco.

Os testes experimentais foram realizados em campo, na empresa INCOMGEL, grande produtora de caulim localizada na cidade de Assunção - PB, a 230 km da cidade da capital João Pessoa, nos dias 09 e 10 de dezembro de 2020.

A cidade de Assunção está localizada no semiárido do nordeste brasileiro, na latitude $7.06^{\circ}$ Sul e longitude $36.66^{\circ}$ Oeste, situada a $586 \mathrm{~m}$ de altitude em relação ao nível do mar, e tem clima tropical típico do semiárido

Grilo (2007), recomenda que o secador solar, quando fixo, esteja posicionado voltado para o norte geográfico, com uma inclinação igual à latitude local mais uma inclinação de $10^{\circ}$ a $15^{\circ}$. Seguindo esta recomendação, neste estudo foi utilizada uma inclinação de $20^{\circ}$.

Para a obtenção dos dados referentes a temperatura do ar e umidade relativa do ar durante o processo de secagem, necessários para o cálculo do rendimento térmico, foi desenvolvido um sistema de medição e aquisição de dados (SMAD) utilizando uma plataforma de prototipagem eletrônica do tipo Arduino com sensores de medição de temperatura e umidade relativa do ar do tipo DHT22. O posicionamento dos sensores durante a realização dos experimentos está ilustrado na Figura 1. Os dados de temperatura e umidade relativa do ar de secagem foram obtidos a cada minuto e gravados em periférico para posterior tratamento. 
Figura 1: Posicionamento dos sensores nos sistemas de secagem solar.

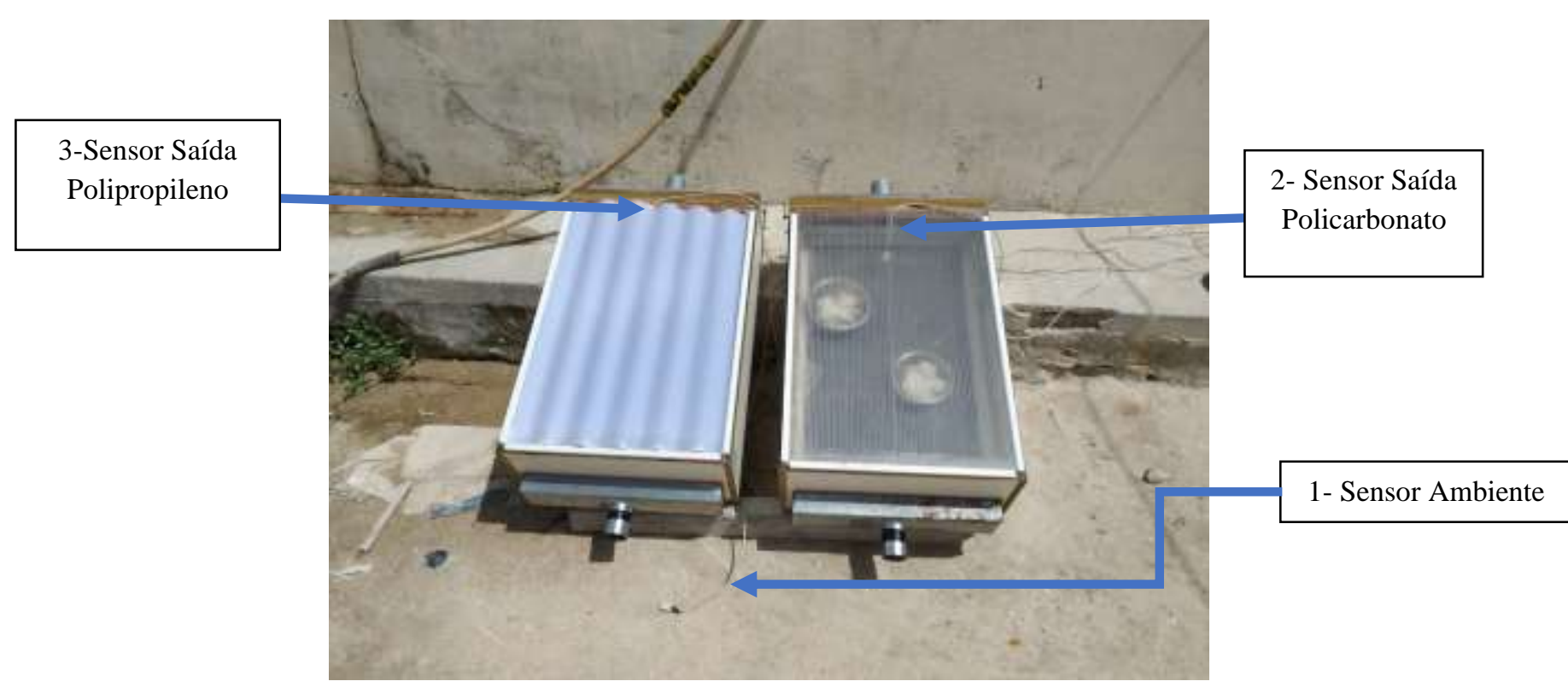

Fonte: Autores.

Os dados de irradiação solar utilizados foram disponibilizados pelo Instituto Nacional de Meteorologia (INMET), sendo que a estação meteorológica da cidade de Patos - PB, foi utilizada como referência, visto que essas cidades estão próximas e localizadas no mesmo microclima regional.

No processo de secagem foram utilizados fragmentos de caulim do beneficiamento da empresa. As amostras foram dispostas no centro do secador e foram pesadas em uma balança digital com resolução de 0,01 g, a cada 60 min.

\subsection{Secagem}

A secagem é uma operação unitária caracterizada pela transferência simultânea de calor e massa entre o ar circundante e o produto a ser seco. Na secagem de minérios e alimentos, em particular de frutas, a redução da quantidade de água ocorre até um nível no qual seu metabolismo e/ou dos microrganismos a ele associados sejam minimizados. (Lima, 1999; Costa, 2008).

A composição mássica de um produto a ser seco é formada por fração de massa de matéria seca e outra de massa de água, como representado na Equação (1).

$$
\mathrm{m}_{\mathrm{t}}=\mathrm{m}_{\mathrm{ms}}+\mathrm{m}_{\mathrm{H} 20}
$$

onde,

$m_{t}-$ massa total do produto, $(\mathrm{g})$

$m_{\mathrm{H}_{2} \mathrm{O}}$ - massa de água contida no produto, $(\mathrm{g})$;

$m_{m s}$ - massa de matéria seca do produto, $(\mathrm{g})$;

A remoção de água durante o processo de secagem é calculada em função do teor de água inicial e final do produto a ser seco e da massa total do produto no início do processo.

O teor de água pode ser expresso em relação a massa de matéria seca ou em relação a massa total do produto a ser seco, como é expresso pelas Equações (2) e (3). 


$$
\begin{aligned}
& X_{b u}=\frac{m_{\mathrm{H}_{2} \mathrm{O}}}{m_{t}} \\
& X_{b s}=\frac{m_{\mathrm{H}_{2} \mathrm{O}}}{m_{\mathrm{ms}}}
\end{aligned}
$$

onde,

$X_{b u}$ - teor de água, em base úmida, do produto (\%);

$X_{b s}$ - teor de água, em base seca, do produto (\%).

Em geral utiliza-se o teor de água em base úmida em situações comerciais, como por exemplo no critério de classificação de frutas, secas ou desidratadas, da Anvisa e de minérios; e o teor de água em base seca é utilizado em trabalhos científicos, com por exemplo na modelagem matemática da cinética de secagem.

Para determinação do teor de água do caulim, as amostras, após a secagem solar, foram levadas a uma estufa de Secagem e Esterilização SL-100 a uma temperatura de $100^{\circ} \mathrm{C}$ por um período de $24 \mathrm{~h}$ para a obtenção da massa de equilíbrio. Em seguida, as amostras eram mantidas sob as mesmas condições por mais um período de $24 \mathrm{~h}$ para a obtenção da massa seca do produto, conforme metodologia empregada por Farias (2011), sendo possível a determinação da massa de água do produto.

\subsection{Rendimento térmico do sistema de secagem}

O rendimento térmico do sistema de secagem foi obtido por meio da aplicação do balanço de energia levando em consideração dados referentes à temperatura e umidade relativa do fluido de trabalho. Como o SMAD desenvolvido mede e registra os dados de temperatura e umidade relativa do ar, essas informações serão utilizadas para calcular o rendimento térmico do sistema durante a realização dos experimentos.

Para isso, faz-se necessário a aplicação do Princípio da Conservação da Energia e de Massa para um volume de controle e da Primeira Lei da Termodinâmica, descritas a seguir:

Princípio de Conservacão de Massa: A taxa temporal de variação de massa contida no interior do volume de controle no instante ( $t$ ) é igual a taxa temporal de fluxo de massa através da entrada (e) no instante (t) menos a taxa temporal de fluxo de massa através da saída (s) no instante (t). Este enunciado pode ser representado simbolicamente como:

onde,

$$
\frac{\mathrm{dm}_{\mathrm{vc}}}{\mathrm{dt}}=\sum \dot{\mathrm{m}}_{\mathrm{e}}-\sum \dot{\mathrm{m}}_{\mathrm{s}}
$$

$\frac{\mathrm{dm}_{\mathrm{vc}}}{\mathrm{dt}}-$ taxa temporal da

variação de massa contida no interior do volume de controle $\left(\frac{\mathrm{kg}}{\mathrm{s}}\right)$;

$\dot{\mathrm{m}}_{\mathrm{e}}$ e $\dot{\mathrm{m}}_{\mathrm{s}}-$ taxas de fluxo de massa instantâneas na entrada e saída, respectivamente $\left(\frac{\mathrm{kg}}{\mathrm{s}}\right)$.

Neste trabalho, será considerado um escoamento unidimensional para o fluido; assim, a taxa de fluxo de massa pode ser calculada pela Equação 5.

$$
\dot{\mathrm{m}}=\rho A V
$$

onde,

$\rho$ - massaespecífica do fluido de trabalho $\left(\frac{\mathrm{kg}}{\mathrm{m}^{3}}\right)$;

A - área através da qual o fluido escoa $\left(\mathrm{m}^{2}\right)$;

$\mathrm{V}$ - velocidade de escoamento do fluido de trabalho $\left(\frac{\mathrm{m}}{\mathrm{s}}\right)$. 
Primeira Lei da Termodinâmica (Lei da Conservação de Energia): A taxa temporal de variação da energia armazenada no interior de um volume de controle no instante $t$ é igual à diferença entre as taxas totais de transferência de energia de entrada $\mathrm{e}$ saída. Em linguagem simbólica, a Primeira Lei da Termodinâmica pode ser representada pela Equação 6.

$$
\frac{\mathrm{dE}_{\mathrm{vc}}}{\mathrm{dt}}=\dot{\mathrm{Q}}_{\mathrm{vc}}-\mathrm{W}_{\mathrm{vc}}+\sum_{\mathrm{e}} \dot{\mathrm{m}}_{\mathrm{e}}\left(\mathrm{h}_{\mathrm{e}}+\frac{\mathrm{v}_{\mathrm{e}}^{2}}{2}+\mathrm{gz}_{\mathrm{e}}\right)-\sum_{\mathrm{e}} \dot{\mathrm{m}}_{\mathrm{s}}\left(\mathrm{h}_{\mathrm{s}}+\frac{\mathrm{v}_{\mathrm{s}}^{2}}{2}+\mathrm{gz}_{\mathrm{s}}\right)
$$

onde,

$\frac{\mathrm{dE}_{\mathrm{vc}}}{\mathrm{dt}}$ - taxa temporal da variação de energia contida no interior do volume de controle $(\mathrm{W})$;

$\dot{\mathrm{Q}}_{\mathrm{vc}}$ - taxa de transferência de calor ao longo da fronteira do volume de controle (W);

$\mathrm{W}_{\mathrm{vc}}$ - taxa de transferência de trabalho ao longo da fronteira do volume de controle (W);

$\dot{\mathrm{m}}_{\mathrm{e}} \mathrm{e} \dot{\mathrm{m}}_{\mathrm{s}}$ - taxas de fluxo de massa instantâneas na entrada e saída, respectivamente $\left(\frac{\mathrm{kg}}{\mathrm{s}}\right)$;

$\mathrm{v}_{\mathrm{e}} \mathrm{e} \mathrm{v}_{\mathrm{s}}$ - velocidade do fluido na entrada e saída, respectivamente, do volume de controle $\left(\frac{\mathrm{m}}{\mathrm{s}}\right)$;

$\mathrm{g}$ - aceleração da gravidade $\left(\frac{\mathrm{m}}{\mathrm{s}^{2}}\right)$;

$\mathrm{z}_{\mathrm{e}}$ e $\mathrm{z}_{\mathrm{s}}$ - valor absoluto da posição vertical da entrada e saída, respectivamente, do volume de controle (m);

$h_{e}$ e $h_{s}$ - entalpia específica do fluido na entrada e saída, respectivamente, no volume de controle $\left(\frac{\mathrm{kJ}}{\mathrm{kg}}\right)$.

Para calcular o rendimento térmico do sistema de secagem proposto neste trabalho, foi considerada a representação esquemática do volume de controle ilustrado na Figura 2.

Figura 2: Representação esquemática do volume de controle.

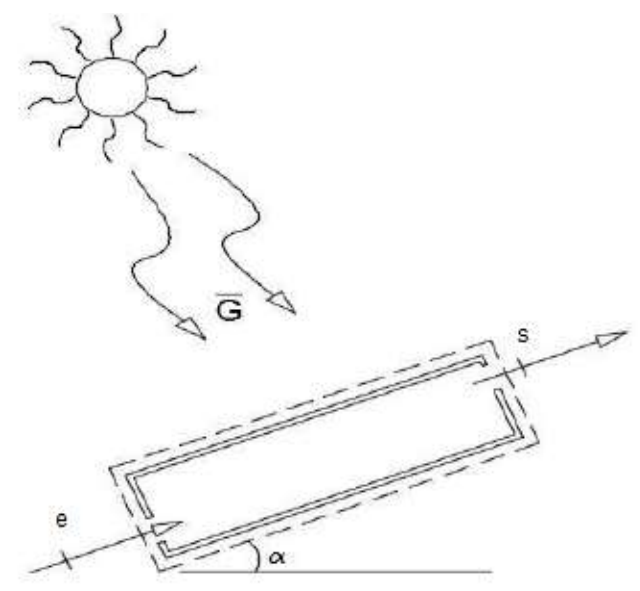

Fonte: Adaptado de Nunes (2016).

Ao analisar o volume de controle para o secador solar proposto, deve-se levar em consideração. Deste modo, a massa de ar que sai é igual a massa de ar que entra mais a massa de água, retirada do caulim, cuja equação matemática é dada por:

$$
\dot{\mathrm{m}}_{\mathrm{s}}=\dot{\mathrm{m}}_{\mathrm{e}}+\dot{\mathrm{m}}_{\text {água retirada do produto }}
$$

onde,

$\dot{\mathrm{m}}_{\mathrm{s}}$ - vazão mássica de ar na saída do volume de controle $(\mathrm{kg} / \mathrm{s})$;

$\dot{\mathrm{m}}_{\mathrm{e}}$ - vazão mássica de ar na entrada do volume de controle $(\mathrm{kg} / \mathrm{s})$; 
$\dot{m}_{\text {água retirada do produto }}$ - vazão mássica da água retirada do caulim $(\mathrm{kg} / \mathrm{s})$.

Aplicando a Primeira Lei da Termodinâmica e considerando que a energia cinética e a energia potencial na entrada e saída do secador solar são iguais, o que é aceitável, dadas as características construtivas e operacionais do equipamento e considerando que o trabalho realizado pelo secador solar é nulo, porque o secador solar não é uma máquina térmica e sim um aparelho térmico, a Equação 6 fica reduzida à Equação 8.

$$
\dot{\mathrm{Q}}_{\mathrm{vc}}+\dot{\mathrm{m}}_{\mathrm{e}} \mathrm{h}_{\mathrm{e}}=\dot{\mathrm{m}}_{\mathrm{e}} \mathrm{h}_{\mathrm{s}}+\mathrm{h}_{\mathrm{v}} \dot{\mathrm{m}}_{\text {água retirada do produto }}
$$

onde,

$\mathrm{h}_{\mathrm{v}}=$ entalpia de vaporização da água na temperatura de saída $\left(\frac{\mathrm{J}}{\mathrm{kg}}\right)$.

Como $\dot{\mathrm{Q}}_{\mathrm{vc}}$ é o $\dot{\mathrm{Q}}_{\text {real }}$, isto é, $\dot{\mathrm{Q}}_{\mathrm{vc}}$ é a energia transferida para o fluido de trabalho e denotando

$$
\dot{\mathrm{E}}_{\mathrm{b}}=\mathrm{h}_{\mathrm{v}} \dot{\mathrm{m}}_{\text {água retirada do produto }}
$$

A Equação 8 pode ser reescrita como:

$$
\dot{\mathrm{Q}}_{\text {real }}+\dot{\mathrm{m}}_{\mathrm{e}} \mathrm{h}_{\mathrm{e}}=\dot{\mathrm{m}}_{\mathrm{s}} \mathrm{h}_{\mathrm{s}}+\dot{\mathrm{E}}_{\mathrm{b}}
$$

Ao aplicar o conceito de eficiência térmica, pela Segunda Lei da Termodinâmica, para um volume de controle e considerando a vazão mássica de entrada e saída diferentes, dadas as características construtivas do equipamento, obtém-se a Equação 11, a qual representa o rendimento térmico do secador solar proposto.

$$
\eta_{\text {secador }}=\frac{\dot{\mathrm{Q}}_{\text {real }}}{\dot{\mathrm{Q}}_{\text {solar }}}=\eta_{\text {secador }}=\frac{\dot{\mathrm{m}}\left(\mathrm{h}_{\mathrm{s}}-\mathrm{h}_{\mathrm{e}}\right)+\dot{\mathrm{E}}_{\mathrm{b}}}{\dot{\mathrm{Q}}_{\text {solar }}}
$$

onde,

$$
\dot{\mathrm{Q}}_{\text {solar }}=\mathrm{A} \cdot \overline{\mathrm{G}}
$$

sendo,

A - área da cobertura transparente do secador solar $\left(\mathrm{m}^{2}\right)$;

$\overline{\mathrm{G}}$ - média de irradiação solar incidente sobre o secador solar durante o processo de secagem $\left(\frac{W}{m^{2}}\right)$.

\subsection{Cálculo da quantidade de massa de água retirada por experimento}

Considerando que durante o experimento, o caulim em todas as situações (cobertura de policarbonato, cobertura de polipropileno e ao ar livre) tiveram a mesma exposição a irradiação solar e durante o mesmo período, é possível comparar a quantidade de massa de água retirada do produto. Para isso, foi desenvolvido uma forma de medir a perda de água do produto em função do tempo total do experimento. Esse indicador mostra a quantidade de água retirada por hora, durante todo o processo. A Equação 14, apresenta os parâmetros necessários para essa determinação:

$$
\Delta \mathrm{m} / \Delta \mathrm{t}=\frac{\mathrm{m}_{\text {inicial }}-\mathrm{m}_{\text {final }}}{\mathrm{t}_{\text {total }}}
$$

Onde:

$\Delta \mathrm{m} / \Delta \mathrm{t}=$ Quantidade de água retirada no intervalo $\Delta \mathrm{t}(\mathrm{g} / \mathrm{h}) ;$

$\mathrm{m}_{\text {inicial }}=$ Massa inicial do produto $(\mathrm{g})$; 
$\mathrm{m}_{\mathrm{final}}=$ Massa final do produto $(\mathrm{g})$;

$t_{\text {total }}=$ tempo total do experimento $(h)$.

\subsection{Cálculo do consumo específico de energia (CEE) dos processos de secagem}

O cálculo do consumo específico de energia, que é a quantidade de energia necessária para evaporar uma unidade de massa de água presente no produto durante o processo de secagem, foi realizado em todos os testes experimentais. A Equação 14 foi utilizada neste trabalho para determinar o consumo específico dos processos de secagem. O Resultado do cálculo do consumo específico de energia foi um dos principais indicadores de eficiência dos sistemas de secagem estudado neste trabalho pode ser calculado pela Equação 15 .

$$
C E E=\frac{E C \cdot\left(100-U_{f}\right)}{M i \cdot \overline{\left(U_{l}-U_{f}\right)}}
$$

Onde:

$\mathrm{CEE}=$ consumo específico total de energia em $\mathrm{kJ} / \mathrm{kg}$ de água evaporada;

$\mathrm{EC}=$ energia consumida na secagem (térmica), $\mathrm{kJ}$;

$\mathrm{Ui}=$ teor de água inicial do produto, \% b.u.;

$\mathrm{Uf}=$ teor de água final do produto, \% b.u.;

$\mathrm{Mi}=$ massa inicial do produto.

\section{Resultados e Discussão}

Durante a realização dos experimentos a velocidade do ar foi mantida em $1,5 \mathrm{~m} / \mathrm{s}$ e a vazão mássica foi de 0,002767 $(\mathrm{kg} / \mathrm{s})$. No primeiro dia do experimento $(09 / 12 / 2020)$, a secagem do minério de caulim ocorreu da 8:00 h às 17:00 h (nove intervalos de hora). Como, ao fim do primeiro dia, as amostras não haviam atingido a massa final desejada, o experimento foi retomado no dia seguinte, iniciando-se às 8:00 h e encerrando às 16:00 h.

Os valores médios de irradiação solar incidente $\left(\mathrm{W} / \mathrm{m}^{2}\right)$ ao longo da realização dos experimentos está ilustrada na Figura 3. As condições meteorológicas da região se mostraram favoráveis em ambos os dias, com altos índices de irradiação solar, pouca nebulosidade e muitas horas de sol.

Figura 3: Valores médios da irradiação solar durante a realização do experimento.

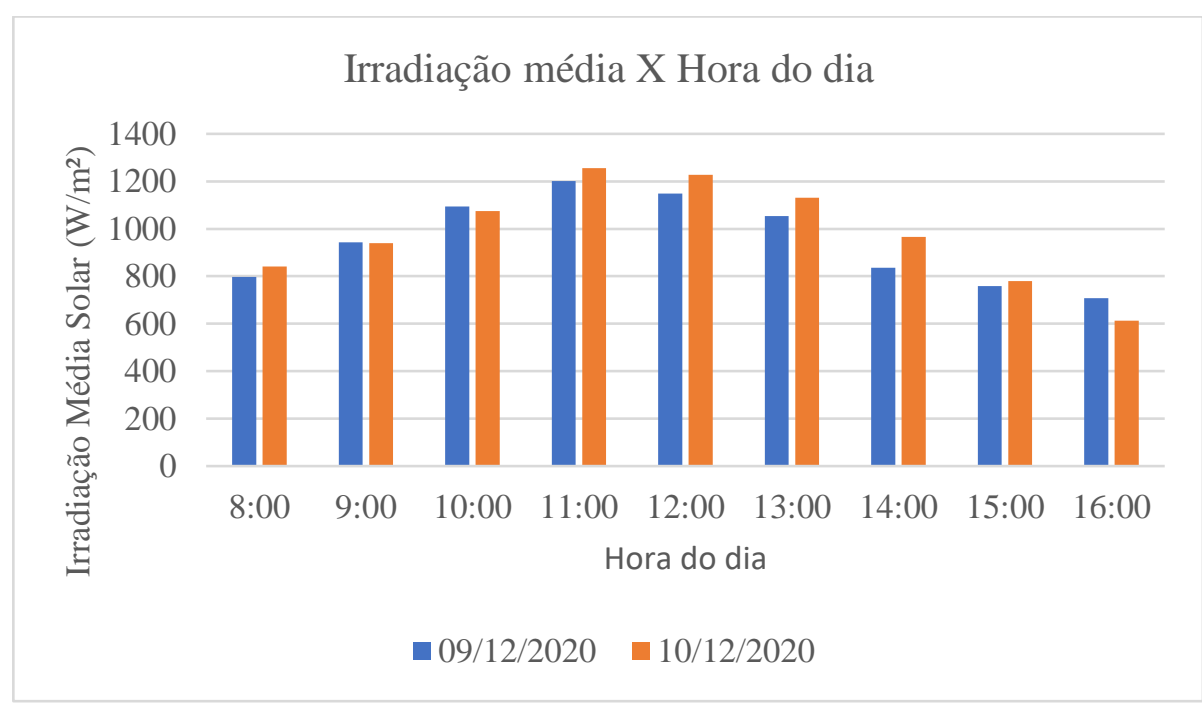

Fonte: INMET. 
A média de irradiação solar ao longo dos dois dias foram muito próximas, sendo no primeiro dia da ordem de 950,00 $\mathrm{W} / \mathrm{m}^{2}$, e no segundo dia, da ordem de $981,00 \mathrm{~W} / \mathrm{m}^{2}$. Ou seja, uma irradiação solar média de aproximadamente $965,00 \mathrm{~W} / \mathrm{m}^{2}$.

A variação de temperatura do ar de secagem medida durante a realização do experimento é apresentada na Figura 4, onde a primeira coluna representa a temperatura do ar de secagem na entrada dos secadores, que é a temperatura do ar ambiente. A segunda coluna representa a temperatura do ar de secagem na saída do secador solar com cobertura de polipropileno e a terceira coluna representa a temperatura do ar de secagem na saída do secador solar com cobertura de policarbonato. As temperaturas máximas na entrada foram $40,32^{\circ} \mathrm{C}$ e de saída no valor de $72,00^{\circ} \mathrm{C}$ respectivamente.

Observou-se que na saída do secador com cobertura de Policarbonato foram obtidos valores de temperatura superior, com média de $55,80^{\circ} \mathrm{C}$ enquanto para o secador com cobertura de polipropileno a média, na saída, foi de $50,18^{\circ} \mathrm{C}$. Isso será refletido em um maior rendimento térmico do secador solar com cobertura de policarbonato

Figura 4: Variação da temperatura do ar nos sistemas de secagem durante a realização do experimento.

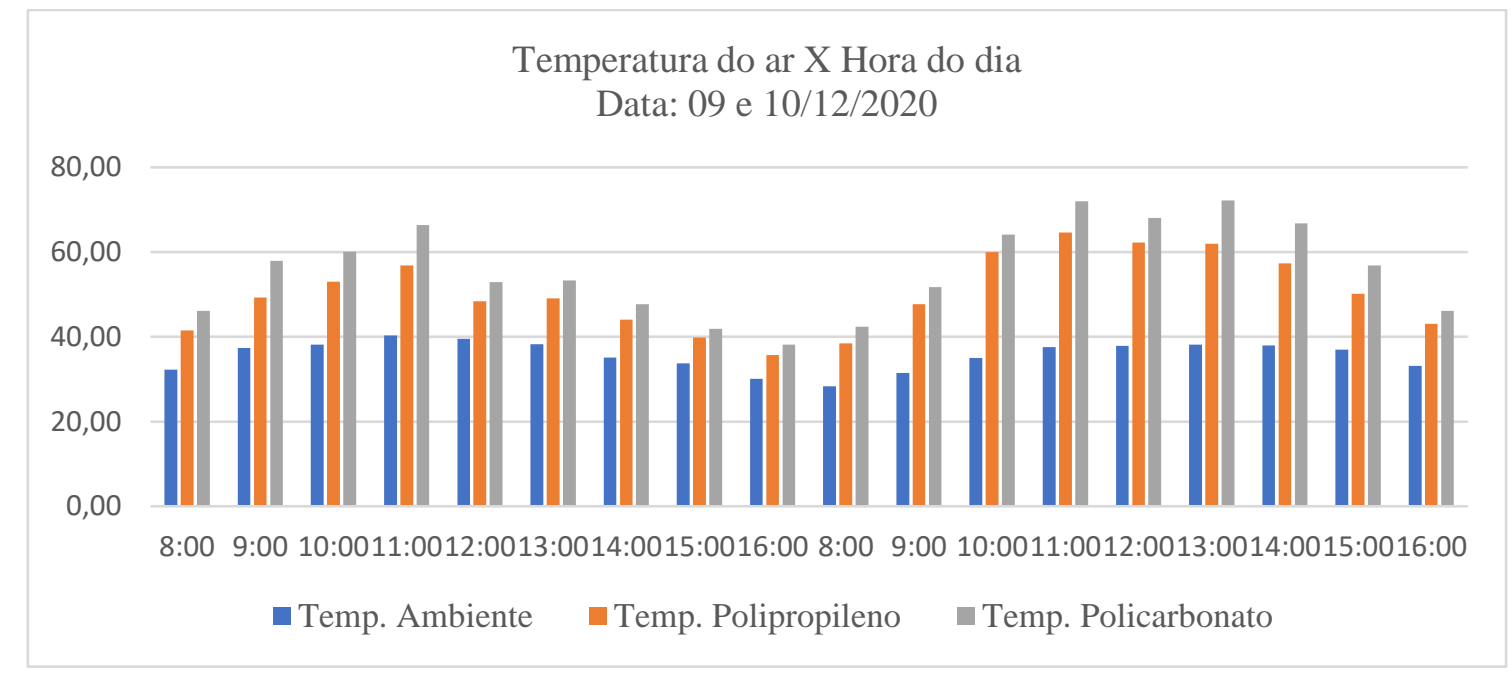

Fonte: Autores.

A variação da umidade relativa do ar de secagem durante a realização do experimento é apresentada na Figura 5. Observou-se no ar de entrada uma umidade superior à de saída. Tal fenômeno está relacionado ao aumento de temperatura do ar dentro do secador, e consequente expansão do mesmo, o que resulta na diminuição da umidade relativa do ar no interior do secador. 
Figura 5: Variação da umidade relativa do ar nos sistemas de secagem durante a realização do experimento.

\section{Umidade relativa do ar x Hora do dia \\ Data: 09 e 10/12/2020}

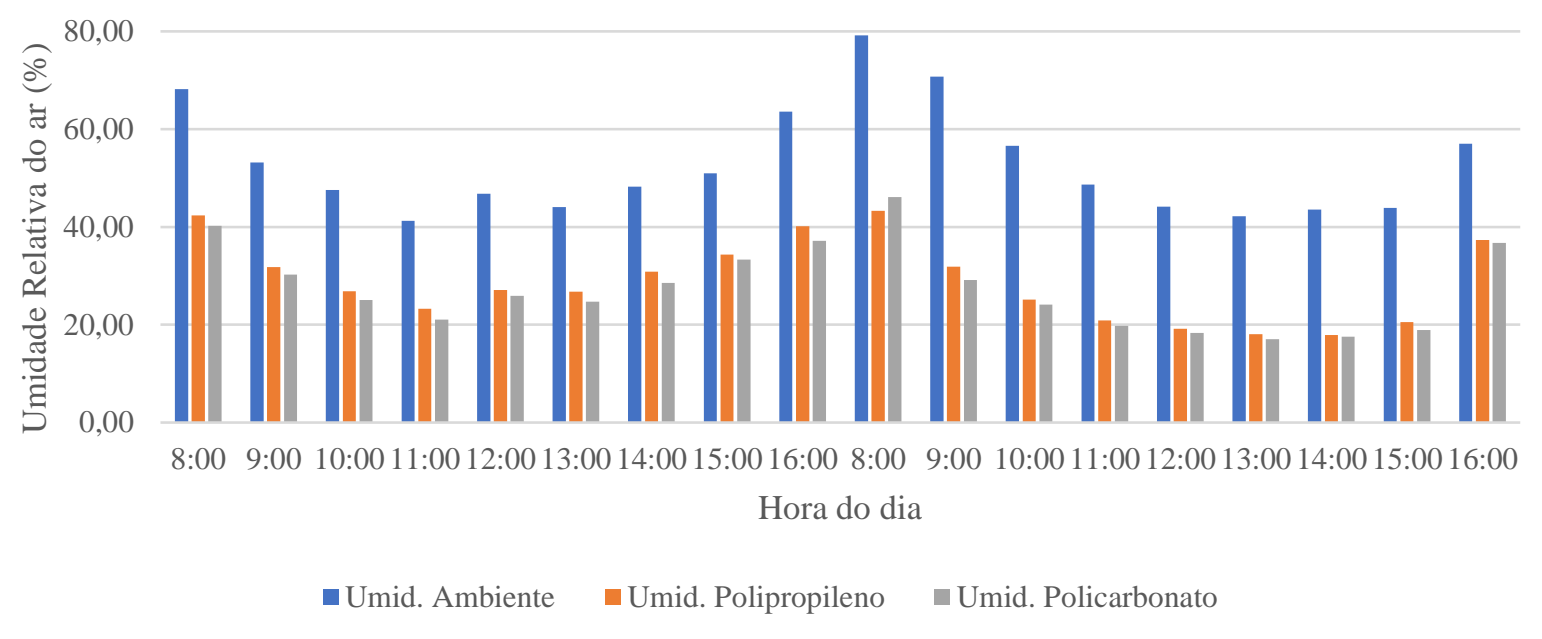

Fonte: Autores.

Neste experimento foram utilizadas duas amostras em cada secador solar. Cada amostra pesava exatamente $200 \mathrm{~g}$ de minério de caulim, e estavam com 30\% de teor de umidade inicial. Este valor foi encontrado a partir da secagem até a obtenção da massa seca em estufa, após a realização do experimento.

Para que o minério caulim esteja em condições de seguir para a próxima etapa de beneficiamento, é necessário que o material esteja com teor de umidade inferior a 5\%. Os valores obtidos para a variação de massa de caulim durante a secagem nos dois secadores são ilustrados na Figura 6.

Figura 6: Teor de umidade em base úmida $x$ tempo de secagem.

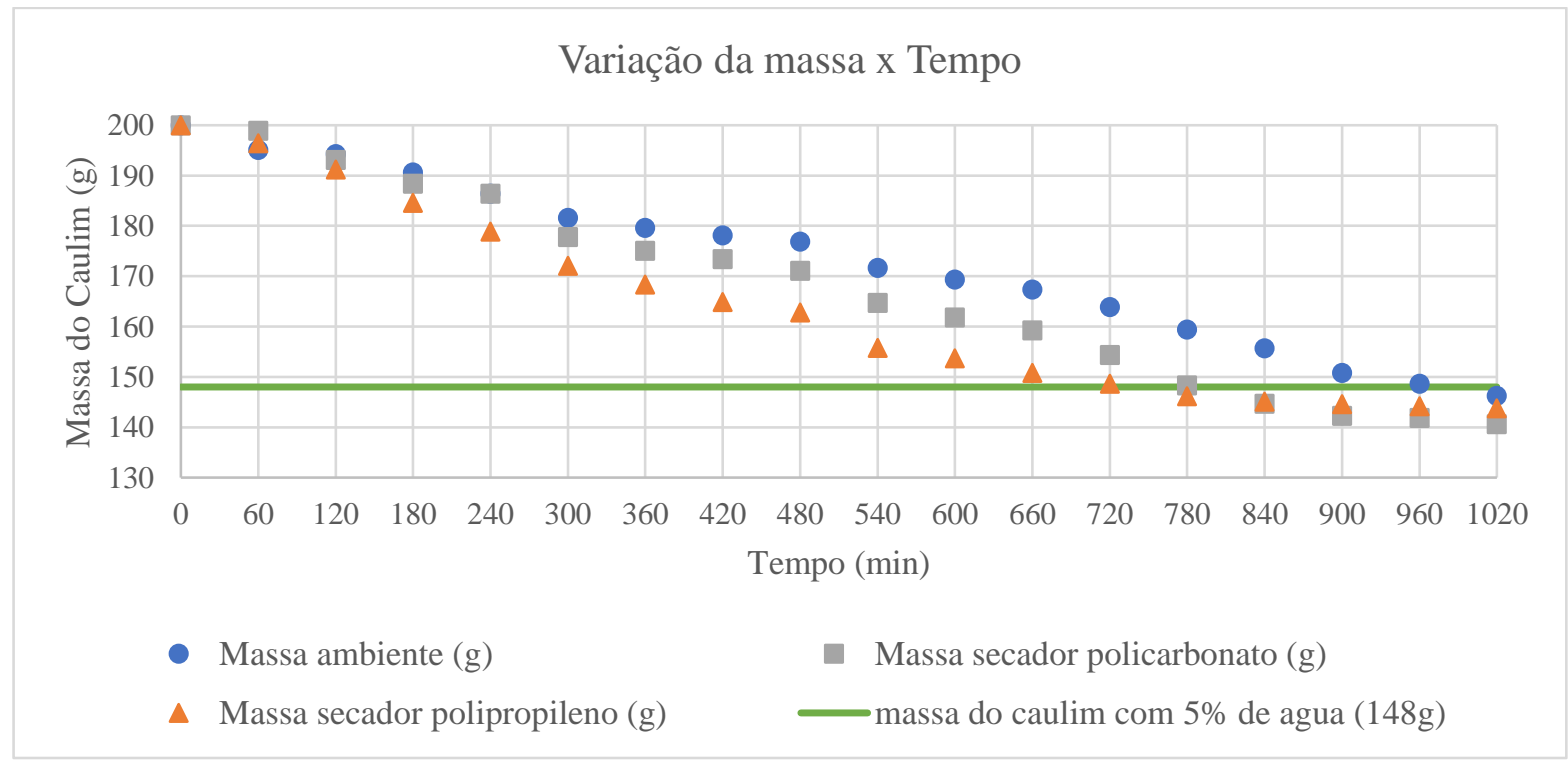

Fonte: Autores. 
Em ambos os secadores, o teor de umidade desejado para o caulim (5\%) foi atingido após 780 min do início da secagem, já na secagem ao ar livre foram necessários $960 \mathrm{~min}$. Portanto, sob as mesmas condições meteorológicas, houve uma redução de 120 min no tempo de secagem do minério de caulim com a utilização de qualquer um dos secadores solares.

Os dados de entalpia do ar de secagem e entalpia de vaporização da água foram obtidos pelo software Computer-Aided Thermodynamic Tables 3 - CATT3 a partir da temperatura, umidade do ar na entrada e saída do sistema de secagem e da pressão atmosférica. A Figura 7 mostra a inserção desses dados no software e as características psicométricas do ar obtidas a partir das curvas psicométricas. Aplicando na Equação 10 é possível calcular o rendimento térmico do equipamento - no caso, de ambos os secadores - e assim avaliar a eficiência do equipamento. A utilização de softwares e ferramentas para estimar as condições do fluido de secagem é uma técnica importante no auxílio da compreensão das características termodinâmicas do processo e permite determinar a entalpia - energia térmica envolvida em uma reação ou processo químico. Comparando as entalpias de entrada e de saída e relacionando com a quantidade de energia recebida pelo processo pelo sol - energia solar - pode-se assim determinar quanto da energia fornecida ao sistema foi transformada em trabalho e resultou na retirada de água do produto.

Figura 7: Dados termodinâmicos do Experimento 2 obtidos pelo CATT.

Computer-Aided Thermodynamic Tables 3

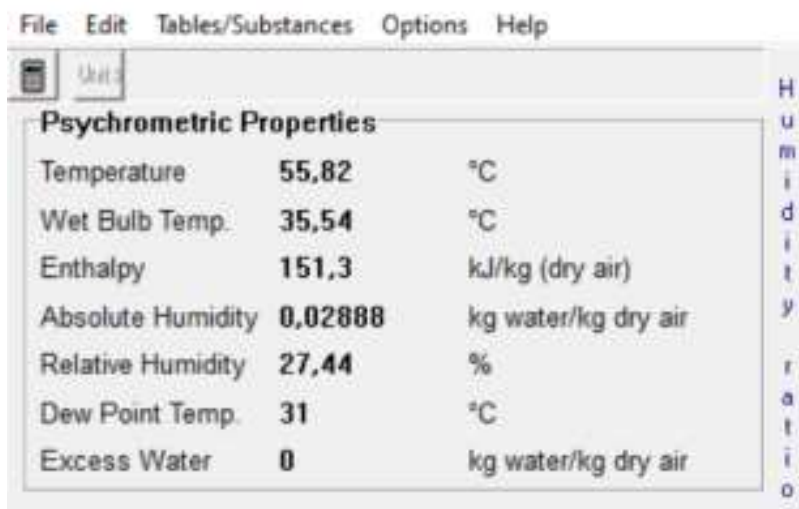

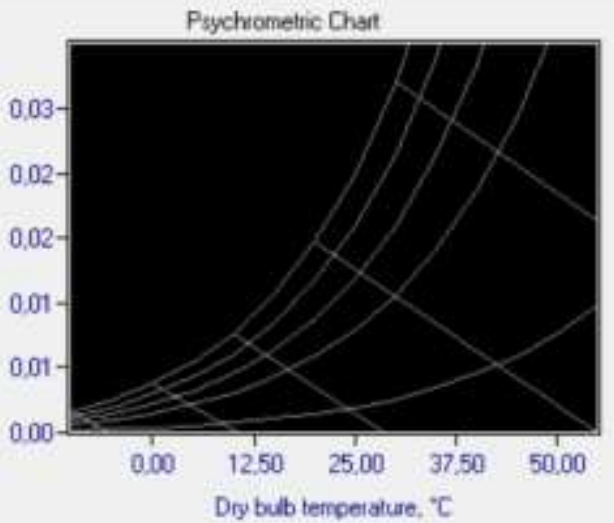

\begin{tabular}{|c|c|c|c|c|c|c|c|c|}
\hline & $\#$ & Temp [I] & $\begin{array}{c}\text { Wet Bulb } \\
\text { Tenro } \\
\text { [Twel! }\end{array}$ & Enthalpy $[\mathrm{H} t]$ & $\begin{array}{c}\text { Absolute Humidiy } \\
\qquad(w)\end{array}$ & $\begin{array}{l}\text { Pelative } \\
\text { Humidity } \\
\text { (chi] }\end{array}$ & $\begin{array}{l}\text { Dew Pont } \\
\text { Temp } \\
\text { [Tdew] }\end{array}$ & $\begin{array}{c}\text { Exess Water [w - } \\
\text { wsat] }\end{array}$ \\
\hline 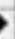 & & ${ }^{\top} \mathrm{C}$ & "C & $\mathrm{kJ} / \mathrm{kg}$ [diy air] & $\mathrm{kg}$ walet $/ \mathrm{kg}$ dy & $\%$ & ${ }^{\circ} \mathrm{C}$ & $\mathrm{kg}$ water/ $/ \mathrm{kg}$ dry \\
\hline & 1 & 35.63 & 27.25 & 105.8 & 0.01946 & 52.77 & 24.5 & 0 \\
\hline & 2 & 50,18 & 32 & 129.6 & 0,0228 & 28,76 & 27,08 & 0 \\
\hline & 3 & 55.82 & 3554 & 151,3 & 0.02868 & 27.44 & 31 & 0 \\
\hline
\end{tabular}

Water Refrigerants Cryogenics Air Ideal Gases Compressibility) Psychrometrics

Fonte: Autores.

Substituindo os valores para o secador com cobertura de policarbonato, tem-se:

$$
\eta_{\text {secador }}=\frac{\dot{\mathrm{Q}}_{\text {real }}}{\dot{\mathrm{Q}}_{\text {solar }}}=\frac{0,0019383 \frac{\mathrm{kg}}{\mathrm{s}}\left(151,3 \frac{\mathrm{kJ}}{\mathrm{kg}}-105,08 \frac{\mathrm{kJ}}{\mathrm{kg}}\right)}{0,28 \mathrm{~m}^{2} \cdot 0,964 \frac{\mathrm{kW}}{\mathrm{m}^{2}}}=33,15 \%
$$


Substituindo os valores para o secador com cobertura de polipropileno, tem-se:

$$
\eta_{\text {secador }}=\frac{\dot{\mathrm{Q}}_{\text {real }}}{\dot{\mathrm{Q}}_{\text {solar }}}=\frac{0,0019383 \frac{\mathrm{kg}}{\mathrm{s}}\left(129,6 \frac{\mathrm{kJ}}{\mathrm{kg}}-105,8 \frac{\mathrm{kJ}}{\mathrm{kg}}\right)}{0,28 \mathrm{~m}^{2} \cdot 0,964 \frac{\mathrm{kW}}{\mathrm{m}^{2}}}=17,07 \%
$$

Foi realizado o cálculo do Consumo específico de secagem, sendo este mais um índice de comparação entre as três situações.

A energia térmica recebida durante a realização do experimento foi de $8.539,03 \mathrm{Wh} / \mathrm{m}^{2}$ no primeiro dia de experimento e $8829,96 \mathrm{Wh} / \mathrm{m}^{2}$ no segundo dia, totalizando $17.368,99 \mathrm{Wh} / \mathrm{m}^{2}$ nos dois dias de experimento. O sistema de secagem solar utilizado nesta pesquisa possui um coletor com área de incidência solar de $0,22 \mathrm{~m}^{2}$. Com essas informações, foi possível determinar a energia térmica incidida, multiplicando-se a irradiação media horaria pela área de incidência do coletor. Com base nessas informações, foi possível determinar o consumo especifico de energia do experimento, que forneceu informações relevantes para a avaliação da etapa de secagem.

Convertendo kWh a energia térmica, o valor da energia utilizada para secagem solar foi de 3,821 kWh. Após a determinação da energia térmica utilizada no experimento, com o auxílio da equação 3.13 apresentada anteriormente no capitulo 3, foi possível determinar o consumo específico de energia (CEE).

Assim, com os dados dos teores de umidade inicial e final do produto, considerando o valor total da amostra do produto utilizado no experimento e a energia térmica recebida pela irradiação solar durante o experimento, foi determinado o consumo específico de energia (CEE). Na Tabela 1 pode ser observado os valores de energia consumida, umidade inicial do produto, umidade final do produto, massa inicial do produto bem como o cálculo do consumo especifico de energia para cada situação do experimento (Cobertura de policarbonato, Cobertura de Polipropileno e Secagem ao ar livre).

Tabela 1: Valores de Energia consumida, teor de umidade inicial do produto, teor de umidade final do produto, massa inicial do produto e consumo específico de energia no Exp para cada situação.

\begin{tabular}{lccccc}
\hline Tipo de sistema de secagem & $\begin{array}{c}\text { EC } \\
(\mathbf{k W h})\end{array}$ & $\begin{array}{c}\text { Ui } \\
(\boldsymbol{\%} \mathbf{b u})\end{array}$ & $\begin{array}{c}\text { Uf } \\
(\boldsymbol{\%} \mathbf{b u})\end{array}$ & $\begin{array}{c}\text { Mi } \\
(\mathbf{k g})\end{array}$ & $\begin{array}{c}\text { CEE } \\
(\mathbf{k W h} / \mathbf{k g})\end{array}$ \\
\hline Cobertura de Policarbonato & 3,821 & 30 & 0 & 0,2 & 63,68 \\
Cobertura de Polipropileno & 3,821 & 30 & 3 & 0,2 & 68,63 \\
Secagem ao ar livre & 3,821 & 30 & 4 & 0,2 & 70,54 \\
\hline
\end{tabular}

Fonte: Autores.

A Tabela 2 apresenta sintetiza os valores obtidos para cada sistema de secagem solar:

$\checkmark$ Rendimento térmico;

$\checkmark$ Quantidade de água retirada do caulim;

$\checkmark$ CEE. 
Tabela 2: Resultados de rendimento térmico, quantidade de água retirada no intervalo de tempo e CEE para o experimento.

\begin{tabular}{lccc}
\hline & $\begin{array}{c}\text { Rendimento térmico } \\
(\boldsymbol{\%})\end{array}$ & $\begin{array}{c}\text { Quantidade de água ret. no } \\
\text { intervalo de tempo }(\mathbf{g} / \mathbf{h})\end{array}$ & $\begin{array}{c}\text { CEE } \\
(\mathbf{k J} / \mathbf{k g})\end{array}$ \\
\hline Secador policarbonato & 33,15 & 3,7125 & 63,68 \\
Secador polipropileno & 17,07 & 3,5125 & 68,63 \\
Secagem natural & - & 3,3563 & 70,54 \\
\hline
\end{tabular}

Fonte: Autores.

É possível concluir que o secador solar com cobertura de policarbonato apresentou um rendimento térmico superior ao secador com cobertura de polipropileno. Observou-se que, apesar de ambos secarem o produto numa velocidade muito próxima, os rendimentos foram bem diferentes. O consumo específico de energia também mostra qual processo foi mais eficiente e necessitou de menor consumo de energia para a realização da secagem.

Os resultados obtidos de temperatura e umidade estão dentro do esperado e observados em alguns trabalhos como Leite Filha (2021) e Costa (2021). Os valores de rendimento térmico também estão coerentes com as características do equipamento e encontrados por Gomes (2017) e Fernandes (2021), mostrando assim a confiabilidade dos resultados.

\section{Conclusões}

Com base nos resultados, pode-se inferir que:

$\checkmark$ A utilização de secadores solares acarretou no aumento da temperatura do ar e redução da umidade relativa do ar de secagem, características favoráveis para a realização do processo de secagem;

$\checkmark \quad$ O tempo de secagem necessário para que o minério de caulim atingisse teor de umidade, em base úmida, de $5 \%$ nos secadores e na secagem ao ar livre foram de $780 \mathrm{~min}$ e $960 \mathrm{~min}$, respectivamente, ou seja, houve uma redução de 240 min no tempo de secagem do minério de caulim com a utilização de secadores;

$\checkmark$ O rendimento térmico do secador com cobertura de policarbonato apresentou valores maiores do que o secador com cobertura de polipropileno

$\checkmark$ Os valores observados dos rendimentos térmicos dos dois sistemas dos secadores estão de acordo com os mencionados na literatura;

Para trabalhos futuros sugere-se realizar testes experimentais com a carga máxima de amostras no equipamento; realizar testes em diversas épocas do ano e analisar a influência dessas variáveis no tempo de secagem e no rendimento térmico do equipamento. Além disso, testes em grande escala, com quantidades de amostra proporcionais as escalas de produção mineral da região são importantes para o desenvolvimento de projetos de grande porte e que atendam às necessidades e demandas da indústria local.

\section{Referências}

Costa, N. L., Leite Filha, M. de S., Conceição, J. A. S. e S. da., Gomes, Í.de A., Santana, V. L., Fernandes, J. F. de S., Lima Junior, C. de, \& Grilo, M. B. (2021) Evaluation of a direct exposure solar drying system for pineapple under meteorological conditions in the northeastern semiarid region. Research, Society and Development, 10, e31910817399

Costa, A. R. S. (2018). Sistema de secagem solar para frutos tropicais e modelagem da secagem de banana em um secador de coluna estática. Tese de Doutorado (Programa de Pós-Graduação em Engenharia Química). Universidade Federal do Rio Grande do Norte, Natal.

Farias, R. P. (2011). Secagem de banana em estufa: efeitos térmicos e geométricos. (2011). Tese de Doutorado (Programa de Pós-graduação em Engenharia de Processos). Universidade Federal de Campina Grande, Campina Grande.

Fernandes, J. F. S. (2021). Desenvolvimento experimental de um secador solar especial com sílica gel como dessecante do ar de secagem. Dissertação de Mestrado. Programa de Pós-Graduação em Engenharia Mecânica, Universidade federal de Campina Grande. 
Gomes, I. de A. \& Grilo, M. B. (2015). Utilização de um Secador Solar de Frutas com Aproveitamento Multienergético na Desidratação de Abacaxi.: Congresso Técnico Científico da Engenharia e da Agronomia.

Gomes, I.A. (2017). Desenvolvimento Experimental de um Secador Solar de Frutas com Aproveitamento Multienergético. 2017. 121p. Dissertação (Mestrado em Engenharia Mecânica). Universidade Federal de Campina Grande, UFCG. Campina Grande, PB. 2017.

Grilo, M. B. (2007). Fundamentos da Energia Solar: conceitos básicos e aplicações. Editora da Universidade Federal de Campina Grande, EDUFCG.

Grim, R. (1958). Clay Mineralogy. New York: McGraw-Hill, (Geological Science Series), p. 29.

Instituto Nacional de Meteorologia. (2020). http:www.inmet.gov.br/portal

Krang, E. G., Onwe, D. N. \& Onda, D. O. (2015). Development of a direct passive solar dryer for crayfish (Procambarus clarkii). International Journal of Engineering Research and Science \& Technology, 4 (2): 153-164.

Kumar, m., Sansaniwal, s. K. \& Hatark, p. (2016). Progress in solar dryers for drying various commodities. Renewable and Sustainable Energy Reviews, 55: 346-360.

Leite Filha, M. de S.., Silva, M. B., Gomes, Í. de A., Grilo, M. B., Costa, N. L., Conceição, J. A. S. e S. da, Santana, V. L., \& Fernandes, J. F. de S. (2021) Development of a flat solar collector for a drying system using factorial experimental design. Research, Society and Development, 10, e39010716755

Lima, A. G. B. (1999). Fenômeno de Difusão em Sólidos Esferoidais Prolatos. Estudo de caso: secagem de banana. 1999. 265p., Tese (Doutorado em Engenharia Mecânica), Universidade Estadual de Campinas, Unicamp. 1999.

Murray, H. H., Keller, W. Kaolins, kaolins, \& kaolins. (1996). In: Murray, H. H., Bundy, W., Harvey, C. Kaolin Genesis and Utilization, The Clay Minerals Society: Boulder, 1-24.

Mustayen, A. G. M. B., Mekhilef, S., \& Saidur, R. (2014). Performance study of different solardryers: a review. Renewableand Sustainable Energy Reviews, $34,463-470$.

Nunes, A. G. (2016) Desenvolvimento Experimental de um Secador Solar Multienergético para Secagem de Frutas. 2016.199 p., Tese (Doutorado em Engenharia Processos) Universidade Federal de Campina Grande.

Nunes, A.G., Gomes, Í de A., \& Grilo, M. B. (2014). Testes Experimentais com Secador Solar de Exposição Direta para Desidratação de Abacaxi. In: VIII Congresso Nacional de Engenharia Mecânica, 2014, CONEM 2014, Anais..., 8, 1-7,

Nunes, A. G., Gomes, I. A., Junior, J. S. S., \& Grilo, M. B. (2013). Estudos para Determinação do Modelo Matemático Representativo de Experimentos com Secagem de Banana Usando Energia Solar e Gás Liquefeito de Petróleo. Revista Magistra, UFSC.

Peneiro, J. C., Melo, L. P., \& Coradi, T. B. (2010). Construção de aquecedor solar de baixo custo sem cobertura: análise experimental da eficiência térmica para vários ensaios. Revista de Ciência e Tecnologia. 10, 18-34.

Proetti, S. (2018). As pesquisas qualitativa e quantitativa como métodos de investigação científica: Um estudo comparativo e objetivo. Revista Lumen, 2.

Santana, V. L. (2017) Beneficiamento de caulim na região do Junco do Seridó/PB e Equador/RN através da classificação de partículas em hidrociclones. 95p. Dissertação (Mestrado em Exploração Petrolífera e Mineral). Universidade Federal de Campina Grande, UFCG. Campina Grande, PB. 2017. 